\title{
ROLE OF CRUSH CYTOLOGY FOR THE DETECTION OF HELICOBACTER PYLORI IN GASTRODUODENAL DISEASES
}

\author{
AHSAN K ${ }^{1}$, HOSSAIN MZ2 ${ }^{2}$ UDDIN MR 3
}

\begin{abstract}
:
Context: A cross-sectional study was carried out at the Department of Pathology, Dhaka Medical Collage, Dhaka and Immunology Laboratory, Laboratory Sciences Division of ICDDR,B, Dhaka during a period of 1 year from July, 2007 to June, 2008 to determine the efficacy of endoscopic crush cytology in the detection of Helicobacter pylori infection in gastroduodenal diseases. Clinically suspected cases of gastro-duodenal lesions and who had not taken antibiotics, omeprazole or bismuth salts for at least three weeks prior to endoscopy were selected. Patients who were clinically and endoscopically suspected of having malignancy were excluded from the study. A total of 110 such subjects were consecutively included in the study. The statistics used to analyze the data were descriptive statistics and components of accuracy test.
\end{abstract}

Results: The sensitivity of crush cytology in correctly diagnosing H. pylori of those who had the disease was $89.3 \%$, while the specificity of the test in correctly differentiating those who did not have H. pylori was $92.6 \%$ when compared against histopathological examination using Giemsa stain. However, a slightly low sensitivity (86.2\%) without compromising with specificity (92.3\%) was obtained when the crush cytology diagnosis was compared against histopathological examination using haematoxylin-eosin ( $H \&$ E) stain.

Conclusion: The study concludes that the diagnostic accuracy of crush smear cytology (sensitivity and specificity) for detection of Helicobacter pylori in gastric biopsy material is comparable to histopathology. Moreover, the technique is very simple, less expensive and less time consuming which gives clinicians added advantage in making a quicker decision.

Key words: Cytology, Helicobacter pylori, Gastroduodenal disease.

J Dhaka Med Coll. 2008; 17(2) : 88-92.

\section{Introduction:}

Gastroduodenal diseases are, perhaps, the commonest diseases in adult population worldwide. Of the several causes/factors Helicobacter pylori infection is now recognized as the culprit organism to induce these diseases. The prevalence of Helicobacter pylori infection varies from country to country with large differences between developed and developing countries ${ }^{1}$. In developing countries like Bangladesh more than $80 \%$ of the populations are infected by this bacterium within two decades of their life ${ }^{2}$. A higher prevalence is found in Bangladesh where there is lack of hygiene, low levels of sanitation, close personal contact and lower socio-economic status $^{3}$. Helicobacter pylori, the spiral-shaped gram-negative bacterium is found to colonize in gastric mucosa or adherent to the epithelial lining of the stomach ${ }^{4}$. The organism was first discovered and reported in 1983 by Warren and Marshall. It has been classified by the International Agency for Research on Cancer (IARC) as a grade-I carcinogen and a definite cause of gastric cancer in humans ${ }^{5}$. The recognition that Helicobacter pylori play a pivotal role in the pathogenesis of several gastroduodenal pathologies makes its diagnosis necessary in many different circumstances ${ }^{6,7}$. Helicobacter pylori resides in the gastric pits and the overlying mucous blanket but not in duodenal type epithelium. Although the decreased $\mathrm{pH}$ of stomach is unfavourable for bacterial colonization, gastric

1. Lecturer, Department of Pathology, Dhaka Medical College, Dhaka.

2. Assistant Professor, Department of Medicine, Dhaka Medical College, Dhaka.

3. Assistant Professor, Department of Gastroenterology, Faridpur Medical College, Faridpur.

Correspondence : Dr. Kajal Ahsan 
colonization with Helicobacter pylori induces histologic gastritis in all infected individuals. Majority of infected individuals remain asymptomatic with histologic gastritis. Rampant prevalence of Helicobacter pylori might be related to the high prevalence of duodenal ulcer and gastric ulcer in our country $8,9,10$. Helicobacter pylori have been found in the duodenum of patient with duodenal ulcer. But when present appears to be confined to areas of gastric metaplasia. This has led Marshall and his associates to suggest that duodenal ulcer may occur in areas of gastric metaplasia infected by Helicobacter pylori ${ }^{11}$. A number of tests may be used to confirm the presence of Helicobacter pylori. These fall into 2 categories; those that rely on non-invasive methods to detect the infection, such as serology, urea breath test, fecal antigen test and invasiverequiring endoscope evaluation includes bacteriologic culture, histopathologic studies, cytological examination of smear, rapid urease test or CLO test and molecular studies ${ }^{5}$. Several studies have shown high sensitivity and specificity of rapid urease test, histology and culture for detection of Helicobacter pylori in gastric biopsy. The sensitivity of rapid urease test is $89-98 \%{ }^{5}, 90 \%{ }^{12}, 90.20 \%{ }^{13}$ and $94.11 \%^{7}$, and the specificity is $(93-100) \%^{5}$, $93 \%^{12}$ and $100 \%{ }^{13}$ and $94.11 \%^{8}$. The sensitivity of histology is $95 \%^{12} 93.60 \%{ }^{13}$ and $93.70 \%^{8}$ and specificity is $99 \%^{12}, 97.70 \%{ }^{13}$ and $75 \%^{8}$. Few studies are done to see the sensitivity and specificity of crush cytological examination of smear. Kaur et al. (2004) studied 150 cases and found sensitivity and specificity of $83.30 \%$ and 100\% respectively. Ahluwalia et al. (2001) studied 50 cases and found sensitivity and specificity of $90 \%$ and $100 \%$ respectively. Pinto et al. (1993) studied 65 cases and found sensitivity $71 \%$. Although the sensitivity and specificity of smear examination is high, the method is not yet fully established as only few studies are done for the identification of $H$. pylori in gastric biopsy by this method. Culture is considered the reference method when comparing the accuracy of non-invasive techniques. However the culture method is most insensitive due to the festidious nature of the organism. Culture is very difficult to perform and requires an enriched transport medium, is expensive and results are delayed (2 - 5 days).

\section{Materials \& Methods:}

Type of study:

Cross-sectional study.

Study area and study period:

This study was carried out at the Department of Pathology, Dhaka Medical Collage, Dhaka and Immunology Laboratory, Laboratory Sciences Division of ICDDR,B, Dhaka during a period of 1 year from July, 2007 to June, 2008.

\section{Study population:}

Clinically suspected cases of gastro-duodenal lesions in Gastroenterology Department, Dhaka Medical College Hospital, Dhaka were the study population.

\section{Enrollment Criteria:}

Patients who were clinically suspected of gastroduodenal lesions and who had not taken antibiotics, omeprazole or bismuth salts for at least three weeks prior to endoscopy, were selected. But the patients who were clinically and endoscopically suspected of malignancy or who has taken antibiotics (e.g. Metronidazole. Amoxicillin, and Clarithromycin), omeprazole or bismuth compounds less than three weeks prior to endoscopy were excluded.

Sample size \& sampling:

A total of 110 subjects who met the criteria described above were consecutively included in the study.

\section{Results:}

Presence of ulcer on endoscopic findings:

Endoscopic findings show that $87.3 \%$ of the subjects had ulcer in the duodenum and $16.4 \%$ in the stomach. Endoscopic diagnosis shows that majority $(87.3 \%)$ of the patients had duodenal ulcer disease, $10 \%$ chronic superficial gastritis and $2.7 \%$ gastric ulcer (Table-I). 
Table-I

Endoscopic findings of the study subjects $(n=110)$

\begin{tabular}{lcc}
\hline Endoscopic findings & Frequency & Percentage \\
\hline Presence of ulcer* & & \\
Stomach & 18 & 16.4 \\
Duodenum & 96 & 87.3 \\
Clinical diagnosis & & \\
Duodenal ulcer disease & 96 & 87.3 \\
Chronic superficial & 11 & 10.0 \\
gastritis & & \\
Gastric ulcer & 03 & 2.7 \\
\hline
\end{tabular}

* Multiple response

Investigation findings:

Table-II demonstrates the investigations findings of the study subjects done to detect the presence of Helicobacter pylori infection. More than $72 \%$ of the patients exhibited positive urease (CLO) test, $60.9 \%$ was positive for serum IgG Ab for $H$. pylori and $50.9 \%$ positive for Crush cytology.

Table-II

Investigation findings of the study subjects $(n=110)$

\begin{tabular}{lcc}
\hline Investigations & Frequency & Percentage \\
\hline $\begin{array}{l}\text { Urease (CLO) test } \\
\text { (positive) }\end{array}$ & 80 & 72.7 \\
$\begin{array}{l}\text { Serum IgGAb for H.pylori } \\
\text { (positive) }\end{array}$ & 67 & 60.9 \\
$\begin{array}{l}\text { Crush cytology } \\
\text { (positive) }\end{array}$ & 56 & 50.9 \\
\hline
\end{tabular}

Histopathological report:

Histopathological report reveals that over half $(50.9 \%)$ of the subjects had positive Giemsa stain for $H$. pylori and $52.7 \%$ haematoxylineosin stain positive for H.pylori (Table-III).
Table-III

Histopathological report of the study subjects ( $n$ $=110$ )

\begin{tabular}{lcc}
\hline Histopathological report & Frequency & Percentage \\
\hline Giemsa stain for H.pylori & 56 & 50.9 \\
Haematoxylin-eosin stain & 58 & 52.7 \\
for $H$. pylori & & \\
\hline
\end{tabular}

Accuracy of crush cytology in diagnosing $H$. pylori:

Table-IVA shows the accuracy of Crush cytology against histopathological diagnosis of $H$. pylori by Giemsa stain. The sensitivity of Crush cytology in correctly diagnosing $H$. pylori of those who have the disease is (50/56) $100=89.3 \%$, while the specificity of the test in correctly differentiating those who do not have $H$. pylori is $(50 / 54)^{-} 100=92.6 \%$. The positive predictive value (PPV) of the test is $(50 / 54)^{\prime} 100=92.6 \%$ and the negative predictive value of the test is $(50 / 56)^{-} 100=89.3 \%$. The percentage of false positive and false negative yielded by the test are $4 / 54^{\prime} 100=7.4 \%$ and $6 / 56^{\prime} 100=10.7 \%$ respectively. The concordance rate of crush cytology with histopathological diagnosis was $81.8 \%$. Table-IVB also shows the accuracy of crush cytology against histopathological diagnosis of $H$. pylori by Haematoxylin-eosin stain. The sensitivity of crush cytology in correctly diagnosing $H$. pylori infection is $(50 /$ 58) $100=86.2 \%$, while the specificity of the test in correctly differentiating those who do not have the infection is $(48 / 52)^{\prime} 100=92.3 \%$. The positive and negative predictive values of the test are $(50 / 54)^{\prime} 100=92.6 \%$ and $(48 / 56)$ $100=85.7 \%$ respectively. The percentage of false positive and false negative yielded by the test are $4 / 54^{\prime} 100=7.4 \%$ and $8 / 56^{\prime} 100=$ $14.3 \%$ respectively. The concordance rate of crush cytology with histopathological diagnosis was $78.2 \%$.

The comparison of accuracy of crush cytology against histopathological diagnosis is given in table-V. 
Table-IVA

Accuracy of Crush cytology against histopathological diagnosis of H. pylori by Giemsa stain

\begin{tabular}{|c|c|c|c|c|c|}
\hline \multirow[t]{2}{*}{$\begin{array}{l}\text { Histopathological diagnosis } \\
\text { (by Giemsa stain) }\end{array}$} & \multirow[t]{2}{*}{$\begin{array}{c}\text { Numberof } \\
\text { cases }\end{array}$} & \multicolumn{2}{|c|}{$\begin{array}{c}\text { Crush cytological } \\
\text { diagnosis }\end{array}$} & \multicolumn{2}{|c|}{$\begin{array}{c}\text { Concordance of Crush } \\
\text { cytology with histopathology }\end{array}$} \\
\hline & & $\begin{array}{l}\text { H. pylori } \\
\text { Present }\end{array}$ & $\begin{array}{l}\text { H. pylori } \\
\text { Absent }\end{array}$ & $\begin{array}{l}\text { No. of } \\
\text { cases }\end{array}$ & $\%$ \\
\hline H. pylori Present & 56 & 50 & 06 & 90 & $81.8 \%$ \\
\hline H. pylori Absent & 54 & 04 & 50 & & \\
\hline Total & 110 & 54 & 56 & & \\
\hline
\end{tabular}

Table-IVB

Accuracy of crush cytology against histopathological diagnosis of $H$. pylori by haematoxylin-eosin stain

\begin{tabular}{|c|c|c|c|c|c|}
\hline \multirow[t]{2}{*}{$\begin{array}{l}\text { Histopathological diagnosis } \\
\text { (by Haematoxylin-eosin stain) }\end{array}$} & \multirow[t]{2}{*}{$\begin{array}{l}\text { Number of } \\
\text { cases }\end{array}$} & \multicolumn{2}{|c|}{$\begin{array}{l}\text { Crush cytological } \\
\text { diagnosis }\end{array}$} & \multicolumn{2}{|c|}{$\begin{array}{c}\text { Concordance of Crush } \\
\text { cytology with histopathology }\end{array}$} \\
\hline & & $\begin{array}{l}\text { H. pylori } \\
\text { Present }\end{array}$ & $\begin{array}{r}\text { H. pylori } \\
\text { Absent } \\
\end{array}$ & $\begin{array}{r}\text { No. of } \\
\text { cases }\end{array}$ & $\%$ \\
\hline H. pylori Present & 58 & 50 & 08 & 86 & $78.2 \%$ \\
\hline H. pylori Absent & 52 & 04 & 48 & & \\
\hline Total & 110 & 54 & 56 & & \\
\hline
\end{tabular}

Table-V

Comparison of accuracy of crush cytology against histopathological diagnosis

\begin{tabular}{lcc}
\hline $\begin{array}{l}\text { Accuracy of } \\
\text { Crush cytology }\end{array}$ & \multicolumn{2}{c}{ Histopathological diagnosis } \\
Giemsa & stain & $\begin{array}{r}\text { aematoxylin- } \\
\text { eosin stain }\end{array}$ \\
\hline Sensitivity (\%) & 89.3 & 86.2 \\
Specificity (\%) & 92.6 & 92.3 \\
PPV (\%) & 92.6 & 92.6 \\
NPV (\%) & 89.3 & 85.7 \\
False positive (\%) & 7.4 & 7.4 \\
False negative (\%) & 10.7 & 14.3 \\
\hline
\end{tabular}

\section{Discussion:}

Since the isolation of Helicobacter pylori by Warren and Marshall in 1983 and recognition of its role in the pathogenesis of several gastroduodenal diseases, its diagnosis has become a necessity. The present study was done with the intention to compare the accuracy of crush cytology with that of histopathological examination. The mean age of the patients was $37.7 \pm 12.3$ years and male to female ratio was roughly $2: 1$. Endoscopic examination revealed that vast majority $(87.3 \%)$ of the patients had duodenal ulcer disease, $10 \%$ chronic superficial gastritis and $2.7 \%$ gastric ulcer. About $73 \%$ of the patients exhibited positive urease (CLO) test, $60.9 \%$ was positive for serum IgG Ab for $H$. pyloriand $50.9 \%$ positive for crush cytology. Out of 110 cases 56 were diagnosed histopathologically as having $H$. pylori infection and 54 did not (when Giemsa stain was used), while 58 were positive and 52 were negative for $H$. pylori when Haematoxylineosin stain was used. The sensitivity, specificity, PPV, NPV of crush cytology in detecting $H$. pylori infection of those who had the disease were fairly comparable to histopathological diagnoses. The sensitivity of crush cytology was $89.3 \%$, while the specificity of the test was $92.6 \%$ when compared against histopathological examination using Giemsa stain. However, a slightly low sensitivity was obtained $(86.2 \%)$ without compromising specificity (92.3\%) when the crush cytology diagnosis was compared against histopathological examination using Haematoxylin-eosin stain. The findings of 
several other studies done to see the sensitivity and specificity of crush cytological examination of smear to diagnose Helicobacter pylori infection are similar to the findings of the present study. Kaur et al. ${ }^{14}$ studied 150 cases and found sensitivity and specificity to be $83.3 \%$ and $100 \%$ respectively. Ahluwalia et al. 15 studied 50 cases and found sensitivity and specificity of $90 \%$ and $100 \%$ respectively. Pinto et al. ${ }^{16}$ studied 65 cases and found a sensitivity of $71 \%$. Nijhawan et al. ${ }^{17}$ also demonstrated crush cytology as fairly sensitive in detecting Helicobacter pylori in gastric biopsy (74\%). They also observed a concordance rate of $76.5 \%$ between the morphologic identification of Helicobacter pylori in crush smears and in tissue sections. These results as well as the findings derived from our study highlight the usefulness of gastric crush cytology in the detection of $H$. pylori infection. In the present study, the percentage of false positive and false negative yielded by crush cytology was very low (7.4\% and $10.7 \%$ respectively) which gives an additional advantage of using crush cytology in diagnosing $H$. pylori infection. Despite the sensitivity and specificity of crush cytology smear examination is high and fairly comparable to histopathology, the method is not yet fully established because of paucity of studies done by this method for the identification of Helicobacter pylori in gastric biopsy. Histopathology is still regarded as the 'gold standard' test for the diagnosis of Helicobacter pylori in biopsy material. But several limitations of this technique discourage its widespread use. Firstly, if the biopsy specimen is too small, poorly oriented, or inappropriately fixed or stained, detection of Helicobacter pylori may not be feasible. Secondly, incase of paucity of bacteria, and in case if they do not have a typical morphology, it is difficult to reach a definitive conclusion and a high chance of misdiagnosis is not unlikely. Of the methods based on endoscopic biopsies, only rapid urease test (CLO test) and crush-smear examination are simple, easy to perform, rapid, cost-effective and result may be available before the patients leave endoscopy suite. Culture is the most specific method for diagnosis of $H$. pylori infection in biopsy specimens. However, its sensitivity is the lowest due to the fastidious nature of the organism. Thus routine culture cannot be considered an acceptable 'gold-standard for general clinical practice. H. pylori is slow growing organism in tissue culture and takes $2-5$ days to become positive. If the biopsy of the stomach is not handled properly, the culture yield can decline, as the organism is fastidious. Moreover, culture is very difficult to perform and requires an enriched transport medium which is expensive and time consuming. Under these circumstances crush-cytology gives positive yield even if the biopsy specimen contains some representative material not sufficient for definitive histological categorization. Endoscopic crush cytology offers a rapid and reliable alternative to molecular and serological detection of this organism. Crush smear cytologic technique of diagnosing Helicobacter pylori in biopsy material is very simple, less expensive, easier to perform, less time consuming and helps in quicker decision for the clinicians. ${ }^{2}$ Besides, crush smear examination is a sensitive method for detection of Helicobacter pylori. But further studies are necessary to establish the method for detection of Helicobacter pylori in gastric biopsy.

\section{Conclusion:}

From the findings of the study and discussion thereof, it can be concluded that diagnostic accuracy of endoscopic crush cytology is high (nearly 90\%). Its specificity is even higher which could help to differentiate subjects who have symptoms of peptic ulcer disease but do not have Helicobacter pylori infection. Endoscopic crush cytology offers a rapid and reliable alternative to serological and histopathological detection of Helicobacter pylori infection in patients of gastroduodenal diseases. Its diagnostic accuracy for detection of Helicobacter pylori is fairly comparable to histopathology. Crush smear cytologic technique of diagnosing Helicobacter pylori in biopsy material is very simple, less expensive, easier to perform, less time consuming and helps clinicians in making a quicker decision. However, as very few studies have been conducted so far. The findings of the present 
study recommend that further studies with large sample size to be done to establish the validity of the method for detection of Helicobacter pylori in gastric biopsy.

\section{References:}

1. Malatey HM, Hoda N. Helicobacter pylori infection: genetic and environmental influences. Best Practice \& Research Clin Gasteroenterol. 2007; 21(2): 205-14.

2. Graham DY, Evans DJ Jr., Peacock J, Baker JT, Schrier WH. Comparision of rapid serological tests (FlexSure HP and Quick Vue) with conventional ELISA for detection of Helicobacter pylori infection. Am J Gastroenterol. 1996; 91 (5): 942-8.

3. Sack RB, Gyr K. Helocobacter infection in developing world. Lancet. 1993. 31: 1274-5.

4. Dooley CP, Cohen H, Patrick L. Prevalence of Helicobacter pylori infection and histologic gastritis in asymptomic persons. N Eng J Med. 1989; 321: 1562-6.

5. Versalovic J. Helicobacter pylori: pathology and diagnostic strategies. Am J Clin Pathol. 2003; 119: 403-12.

6. Graham DY, Malati HM, Evans DG, Evans DJ Jr., Klein PD, Adam E. Epidemiology of Helicobacter pylori in an asymptomic population in the United Satets: effect of age, race and socioeconomic status. Gastroenterology. 1991; 100 (6): 1495-501.

7. Glupezynski Y. Helicobacter pylori: an overview of microbiological and serological diagnosis. $\mathrm{Br}$ Med Bull. 1998; 54(1): 175-86.

8. Talukder SI. Association of Helicobacter pylori with gastric cancer and other gastroduodenal lesions. Mymensingh Med J. 2000; 12(1): 33-5.
9. Hussain M. Histological changes in different gastroduodenal lesion in relation to Helicobacter pylori. [M.Phil. thesis]. Dhaka: IPGMR, University of Dhaka. 1999.

10. Ahmed N. Gastric metaplasia in the duodenum: role of inflammation and Helicobacter pylori. [M.Phil. thesis]. Dhaka: IPGMR, University of Dhaka. 1999.

11. Marshall BJ, Warren JR. Unidentified curved bacilli in the stomach of patients with gastritis and peptic ulceration. Lancet. 1984; 16: 1311-4.

12. Vakil N, Rhew D, Soil A, Ofman JJ. The castEffectiveness of diagnostic testing strategies for Helicobacter pylori. Am J Gastroenterol. 2000; 119: 403-12.

13. Megraud F. Diagnosis of Helicobacter pylori. Baillieres Clin Gastroenterol. 1995; 9(3): 507-18.

14. Kaur G, Madhavan M., Basri AH, Hussain MS, Yatiban MK, Naing NN. Rapid diagnosis of Helicobacter pylori infection in gastric imprint smears. Southeast Asian J Trop Med Pub Health. 2004; 35: 676-80.

15. Ahluwalia C, JainMehta G, Kumar N. Comparison of endoscopic brush cytology with biopsy for detection of Helicobacter pylori in patients with gastroduodenal disease. Indian J Pathol Microbiol. 2001; 44: 283-8.

16. Pinto M, Levine RH, Shaw-Stiffel T. Detection of Helicobacter pylori by Papanicolaou-stained touch imprint: a comparison with histologic examination. Am J Gastroenterol. 1993; 88 (8): 1300-1.

17. Nijhawan R, Kochhar R, Panigrahi D, Radhika $\mathrm{S}$, Malik AK, Mehta SK. Identification of Helicobacter pylori by endoscopic crush cytology. Ind J Gasteroenterol. 1993; 12: 45-6. 